\title{
ABORDAGEM TERRITORIAL NO PLANEJAMENTO PÚBLICO FEDERAL NO BRASIL A PARTIR DOS ANOS 1990: UMA ANÁLISE DA ATUAÇÃO DE EMPRESAS DE CONSULTORIA*
}

Alcides Manzoni Neto**

Resumo: Ao longo dos anos 1990 e início dos anos 2000 assistiu-se a instrumentalização de um planejamento territorial federal setorial, privatizado e fundamentado em uma concepção instrumental do espaço geográfico, funcional aos interesses de uma pequena parcela dos agentes que usam o território brasileiro. Nesse contexto, alguns estudos elaborados por agentes privados (em sua maior parte), porém sob responsabilidade do Estado brasileiro, para operacionalizar e racionalizar o planejamento merecem uma atenção dentro das pesquisas geográficas. Desde o período em questão até os dias de hoje, nota-se como a competitividade territorial e noções como a de desenvolvimento sustentável têm norteado o planejamento público, entronizadas muitas vezes por empresas transnacionais de consultoria, visando legitimar uma dada visão de modernidade para o território brasileiro.

Palavras-chave: novos usos do território brasileiro, planejamento territorial, empresas de consultoria, competitividade territorial, informação.

\section{THE TERRITORIAL APPROCH IN THE FEDERAL PUBLIC PLANING IN BRAZIL BEGINNING ON 1990: AN ANALYSIS ON THE PERFORMANCE OF CONSULTING FIRMS}

Abstract: Along the 1990 s and early 2000 s the manipulation of a federal territorial planning sector, privatized and based on an instrumental conception of geographical space, functional to the interests of a small number of agents that use the Brazilian territory, was observed. In this context, some studies prepared by private agents (mostly), although under the responsibility of the Brazilian State to operationalize and rationalize this planning, deserve a special attention within the geographical researches. Since the appointed period until today, it is noted how the territorial competitiveness and notions such as the sustainable development have guided the public planning, often enthroned by transnational consulting firms in order to legitimize a particular vision of modernity to the Brazilian territory.

Keywords: new uses of Brazilian territory, territorial planning, consulting firms, territorial competition, information.

\section{Introdução}

Compreender algumas das novas feições do planejamento federal "modernizado" se apresenta como uma via de análise dos novos usos do território brasileiro em anos recentes. Ao passo que há uma instabilidade do espaço brasileiro, a tarefa de investigar como e a partir de quais meios o Estado brasileiro propõe pensar o futuro do território é de fundamental importância.
Em anos recentes, nota-se que novos pressupostos teóricos, novas ferramentas de operacionalização, novos aparatos institucionais e novas normas têm reconfigurado a metodologia do planejamento federal no Brasil. Ao longo dos anos 1990 e início dos anos 2000, assistiu-se instrumentalização de um planejamento territorial setorial, privatizado e

\footnotetext{
* Texto elaborado a partir da dissertação de mestrado intitulada $O$ novo planejamento territorial: empresas transnacionais de consultoria, parcerias público-privadas e uso do território brasileiro, sob orientação da Prof Dr $^{a}$ Adriana Maria Bernardes da Silva, no Programa de Pós-graduação em Geografia do Instituto de Geociências, Universidade Estadual de Campinas (Unicamp), e defendida em 2007.

** Doutorando do Programa de Pós-graduação em Geografia na Universidade Estadual de Campinas (UNICAMP). E-mail: alcides.neto@ige.unicamp.br.
} 
fundamentado em uma concepção instrumental do espaço, funcional aos interesses de uma pequena parcela dos agentes que usam o território. Nesse contexto, foram analisados alguns estudos conduzidos por agentes privados (em sua maior parte), porém sob responsabilidade do Estado brasileiro, para operacionalizar e racionalizar o planejamento territorial segundo novos parâmetros de ação.

Imbuídos de um viés neoliberal, os planejadores recorrem cada vez mais a conceitos e práticas vindos da teoria da administração, da Economia Espacial, da Ciência Regional, bem como a um conjunto cada vez mais vasto de empresas de consultoria, cujo poder é crescente no mundo. Esses agentes, apropriando-se de pressupostos teóricos mais afeitos a ideologias do que a práticas científicas, produzem novos discursos que valorizam porções estratégicas e competitivas do território brasileiro. Nesse contexto, grandes estudos sobre o território brasileiro ganham evidência: primeiramente aquele conduzido pelo Consórcio Brasiliana, denominado "Identificação de Oportunidades de Investimentos Públicos e/ou Privados", que ficou conhecido como "Estudo dos Eixos" (realizado entre 1998 e 1999) - visto por alguns como uma base para a "retomada do planejamento territorial" -, e o "Estudo de Revisão dos Eixos Nacionais de Integração e Desenvolvimento" (realizado em 2002).

No presente artigo, são traçadas algumas considerações sobre os referidos estudos a partir de dois pontos principais. Primeiramente, destaca-se a participação decisiva de empresas de consultoria na elaboração de tais análises, sobretudo BoozAllen \& Hamilton Consulting; Boucinhas \&
Campos Consultoria de Gestão, e Monitor Group. Em segundo lugar, ressalta-se como a denominada abordagem territorial tem se tornado o eixo central desse planejamento, inclusive como um recurso para aperfeiçoar variadas estratégias de competitividade.

A partir da análise de alguns conceitos basilares apresentados nos referidos estudos, de esquemas e propostas norteadoras de investimentos, avalia-se a importância das consultorias nesse processo de verdadeira desconstituição do planejamento público (VAINER, 2007) nos anos 1990 e até meados dos anos 2000 . Também se questiona em que medida essas proposições vão ao encontro de uma proposta de construção de um projeto verdadeiramente nacional, uma vez que as novas normas de ação que atendem pelos nomes de desenvolvimento local e sustentável, planejamento estratégico e competitividade - entronizados pelas consultorias - contribuem em muitos casos para pressionar os fundamentos da Federação, pois são verdadeiros combustíveis para a guerra dos lugares (SANTOS, 2002), levando à alienação de porções do território nacional e, consequentemente, à fragmentação territorial.

\section{Os anos 1990 e os novos projetos de modernidade do território}

A década de 1990 foi marcada por profundas modificações na estrutura normativa e regulatória no Brasil, visando viabilizar um dado projeto de modernidade para o país, condizente sobretudo com o receituário do Consenso de Washington. O Programa Nacional de Desestatização, a instauração do Conselho de Reforma do 
Estado (criado pelo Decreto no 1.738/96) e a criação de diversas Agências de Regulação se apresentam como exemplos de uma nova racionalidade modernizadora que passou a imperar na formação socioespacial brasileira. Procurando garantir a viabilidade e a fluidez de porções do território às demandas do mercado mundial, os sucessivos governos da década em questão levaram a cabo um processo de reestruturação do arranjo normativo pretérito, adotando como pressupostos alguns modelos e conceitos "importados" da experiência norte-americana e europeia de reforma do Estado.

Desse modo, o processo de reforma do Estado empreendido no Brasil foi ditado pelas novas condições que passaram a se conformar nos países centrais do sistemamundo, a partir da década de 1980. Com a revisão das políticas de nacionalização europeia e das políticas de regulação americanas, a postura desenvolvimentista e interventora do Estado brasileiro, até então adotada, foi veementemente rechaçada. Deuse lugar "a uma série de transformações introduzidas mediante os processos de privatização (ou reprivatizações) na Europa e de desregulação (deregulation) nos Estados Unidos" (MATTOS, 2002, p. 48). Emergiu um novo regime regulatório no âmbito mundial que:

[...] privilegiando os fluxos transnacionais de capital, torna incertos os controles regulatórios destinados a proteger as economias nacionais. É a chamada desregulação, que abriga oportunidades mais fecundas para os agentes da globalização (SILVEIRA, 1999, p. 244).

No Brasil, a partir de 1995, sucederam-se uma série de emendas constitucionais e leis destinadas a reformular o aparato jurídico-institucional, com vistas a implementar e garantir as privatizações, a concessão de serviços públicos a empresas de capital privado e a flexibilização de monopólios estatais na administração de infraestruturas e serviços. Logo, embora encontremos no discurso inerente à desregulação uma abolição ou suspensão de regulações governamentais (CERNY, 1991), o que se observa são elementos que sugerem se tratar na verdade de uma neo-regulação (SILVEIRA, 1999), na medida em que se criam novas normas rígidas visando garantir uma fluidez e porosidade (ARROYO, 2001) a determinados agentes na condução de suas políticas territoriais.

Assiste-se na verdade a uma ressignificação das políticas normativas e regulatórias do Estado, uma vez elas são determinantes para o comportamento estratégico das Corporações Transnacionais, as quais, buscam explorar as diferenças nos regimes regulatórios nacionais na busca por uma vantagem competitiva global. (DICKEN, 1992). Manifestam-se normas crescentemente rígidas, porque fiéis à manutenção dos interesses de grupos empresariais hegemônicos, instrumentalizando o território. Dessa maneira, vê-se ampliar um processo em que "o território é causa de maior desigualdade entre firmas, instituições e sobretudo entre os homens" (SANTOS, 1998, p. 105-106).

Desempenhando um papel de importância crescente neste processo encontram-se as empresas transnacionais de consultoria. Uma vez que elas detêm um conjunto de informações estratégicas e valiosas sobre os lugares, seus serviços tornam-se insumos fundamentais nas estratégias corporativas, na busca pela 
fluidez mediante novos marcos normativos nacionais. Como nota Dicken (1992, p. 308):

A real existência de uma estrutura regulatória pode ser percebida como uma oportunidade avaliável para as Empresas Transnacionais alcançarem vantagens decorrentes das diferenças regulatórias entre os Estados por meio da mudança de atividades entre localizações, de acordo com as diferenças no arranjo regulatório.

Todavia, Silveira (1999, p. 251) assevera que "entre os territórios 'luminosos' e aquelas formações socioespaciais de maior rigidez jurídica e, portanto, letárgicas do ponto de vista político-financeiro, haveria todo um leque de lugares de diferentes graus de globalização". Desse modo, a identificação de vantagens competitivas entre os lugares manifesta-se como um dos motores das estratégias empresariais, colocando as consultorias, detentoras destas informações, em posição de destaque.

\section{Caracterizando transnacionais de consultoria no atual período histórico}

As empresas transnacionais de consultoria tornaram-se nas últimas décadas agentes pretensamente imprescindíveis na reorientação das ações públicas no Brasil e no mundo no atual período histórico (SILVA, 2001). A busca incessante por fluidez e competitividade faz com que as empresas recorram a especialistas vistos como capazes de darem conta das novas problemáticas da globalização. Estes agentes compõem um setor presente desde longa data no mercado mundial de compra e venda de informações estratégicas, porém hoje se destaca sua contribuição para que a chamada "inteligência" mundial se submeta às leis inexoráveis da estratégia (DÉTRIE, 1989).

As empresas de consultoria são proclamadas como as grandes catalisadoras das transformações necessárias a um funcionamento empresarial que seja coerente com as novas demandas da globalização. Quando uma empresa contrata os serviços de uma consultoria, ela procura tomar consciência de seus problemas organizacionais e dos meios de superá-los, ações as quais não alcançaria sozinha (STERN; TUTOY, 1995). Assim, a ação das consultorias está associada a uma economia de tempo, apresentada como variável crucial porque intimamente relacionada ao valor de uma informação (DANTAS, 2002).

Há, neste sentido, uma busca incessante por parte das empresas em alcançar níveis crescentes de conhecimento, inclusive sobre as virtualidades dos lugares. Daí a crescente expansão das consultorias no mundo, pois elas comercializam conhecimentos apresentados como mercadorias, tornando-se, assim, cruciais na delimitação de novas fronteiras de competitividade no mercado mundial.

Com papel de destaque no Brasil e no mundo, estas empresas figuram entre os maiores grupos empresariais mundiais, de modo que as líderes crescem a uma taxa média de vinte por cento ao ano, "o que as coloca entre os setores econômicos mais rentáveis do período" (DONADONE, 2001, p. 1). ${ }^{1}$ Considera-se assim, que a grande empresa de consultoria comercializa:

\footnotetext{
${ }^{1}$ O autor destaca que "em 1995, estima-se que o mercado mundial de consultorias em gestão organizacional alcançou a cifra de 40 bilhões de
} 
[...] uma informação sigilosa que, em última instância, é também uma importante manifestação do poder contemporâneo (as informações que circulam em grande quantidade são banais e de fácil acesso). O segredo das missões de conselho é um dado estratégico fundamental para 0 denominado bom desempenho das ações, repercutindo em ganhos maiores de competitividade e, assim, ampliando 0 poder político das grandes empresas (SILVA; MANZONI NETO, 2008, p. 56).

As empresas de consultoria podem ser caracterizadas de acordo com sua especialidade. Destacam-se as Accounting Firms - que atuam na auditoria contábil, na orientação sobre questões jurídicas e orientação sobre temas relacionados à gestão das empresas - e as empresas especializadas em estratégia, novas formas de estrutura organizacional e performance financeira (DONADONE, 2001). São sobretudo estas últimas que veem ampliado seu papel na elaboração de planos de intervenção territorial. Deste modo, se manifestam como agentes produtores e distribuidores de informações estratégicas sobre o funcionamento dos territórios nacionais, as quais se apresentam como recurso estratégico, utilizado de forma seletiva e hierárquica (SILVA, 2001).

Envolto no discurso de modernização das relações, há em muitos dos serviços de consultoria de estratégia, uma nova forma de imposição de uma lógica hegemônica do conhecimento, inclusive do território. Para Meneses (2004, p. 742), "na maioria dos casos, as consultorias não são um diálogo de saberes, mas um monólogo dentro do campo científico ocidental". Assim, contribuindo para a permanência das relações de subordinação

dólares e em 2000 o valor já superava os 100 bilhões" (DONADONE, 2001, p. 2). dos países periféricos aos países centrais (MENESES, 2004), as empresas de consultoria ganham força e, por meio de uma atuação ativa nos países do "Sul", garantem a ampliação da divisão do trabalho (social e territorial) baseada na informação. Há, portanto, uma grande verdade na afirmação de Dezalay (1994, p. 300): "este novo mercado internacional de consultoria $[. .$.$] se$ tornou o cadinho em que se formam as novas normas e instituições do capitalismo internacional".

No Brasil, embora algumas das principais empresas globais de consultoria já atuem há muito tempo, suas intervenções cresceram acentuadamente a partir da década de 1990, em decorrência das implicações de ordem política, técnica, organizacional e jurídica provenientes do processo de Reforma do Estado. Assim sendo, esses agentes, principalmente transnacionais, passaram a ser vistos pelos sucessivos governos do período como detentores de um conhecimento imprescindível para a reorientação das funções do Estado. Neste processo, o planejamento territorial estatal passou por um "remodelamento" como consequência dos novos conteúdos conceituais e instrumentais fornecidos, sobretudo, pelas ações destas consultorias.

\section{Convocadas para legitimar um} projeto de viabilização do território nacional às pretensões modernizantes do Estado e de determinados agentes hegemônicos, estas empresas se valeram, inclusive, de um instrumental teórico proveniente das concepções econômicas e espaciais de mais de quatro décadas atrás, com destaque para os aportes da Economia Espacial e da Ciência Regional. 


\section{As consultorias propagam o ideário da competitividade territorial}

Atualmente, espera-se que um dos objetivos do planejamento territorial seja contribuir para a construção de um projeto nacional. Logo, o conhecimento dos usos atuais do território e a identificação de novas possibilidades de desenvolvimento socioespacial se apresentam como um recurso imprescindível, sendo que muitos agentes - como consultores estratégicos podem fornecer valiosas contribuições. Porém, cabe questionar-se em que medida análises dessa natureza concorrem para usos mais solidários e justos do território ou se apenas oferecem subsídios para políticas agressivas das grandes empresas no território brasileiro.

Durante boa parte dos anos 1990 e início dos anos 2000, constata-se uma terceirização do planejamento territorial federal, uma vez que grandes empresas de consultoria (principalmente internacionais) foram contratadas para a elaboração de estudos de planejamento ${ }^{2}$ e para definir diretrizes de ações governamentais. É nesse contexto que problematizamos aspectos da atuação do Consórcio Brasiliana, constituída em 1998 e que tinha como participante a empresa de consultoria Booz-Allen \& Hamilton e o Consórcio Monitor Group/Boucinhas \& Campos, contratado pelo governo brasileiro em 2002. Destaca-se que embora já tenham se passado muitos anos desde a elaboração dos referidos estudos, determinadas propostas introduzidas ainda norteiam o planejamento público, algumas

\footnotetext{
2 A contratação de consultores catalães para a elaboração do Planejamento Estratégico do Rio de Janeiro, em 1993, talvez seja o exemplo mais emblemático no caso brasileiro. A este respeito ver Compans (2005); Lima Jr, (2003) e Vainer (2000).
}

com muito vigor, como as relacionadas à necessidade de valorização da competitividade e do desenvolvimento sustentável.

Durante os oito anos do governo Fernando Henrique Cardoso (1995-2002), procurou-se facilitar a inserção de pontos eleitos do território brasileiro nos mercados internacionais. A tarefa de redimensionar as ações do planejamento esteve sob responsabilidade do Banco Nacional de Desenvolvimento Econômico e Social (BNDES) e do Consórcio Brasiliana ${ }^{3}$ contratado em 1998.

Participante desse consórcio, a BoozAllen \& Hamilton é uma empresa privada, com sede em McLean (Virginia), nos Estados Unidos, fornecendo serviços às principais corporações transnacionais e a governos em todo o mundo. Está presente em diversos países, com lucros anuais em tono de US\$ 5 bilhões (dados de 2010) possui mais de 26 mil funcionários e figura entre as cinco mais Prestigiosas Firmas de Consultoria do mundo, segundo o Vault Guide to the Top 50 Management and Strategy Consulting Firms 2011, uma referência no setor.

\footnotetext{
${ }^{3}$ Foi constituído pela filial brasileira de uma das maiores empresas de consultoria do mundo, a Booz-Allen \& Hamilton Consulting, pela Bechtel International Inc., que figura entre as principais empresas de construção civil do mundo, e por um grande banco internacional, o Banco ABN Amro S. A. Este consórcio produziu, após um ano de sua constituição, um estudo denominado "Identificação de Oportunidades de Investimentos Públicos e/ou Privados", ficando conhecido como Estudo dos Eixos. O Consórcio Brasiliana valeu-se da proposta de conceitualização de Eixo contida no Edital de Licitação (lançado pelo BNDES em 1997) e promoveu a equivalência entre os eixos e a noção de região de planejamento definida por Boudeville (1970). A importância desse estudo deve-se ao fato de ter culminado na orientação metodológica e de investimentos do Programa do segundo Plano Plurianual do governo Fernando Henrique Cardoso, o "Avança Brasil" (2000-2003) e ainda por ter sido visto como uma base para a "retomada do planejamento territorial" (ABLAS, 2003).
} 
Fundamentado no conceito de desenvolvimento sustentável e numa abordagem que priorizava a orientação voltada ao mercado e aos negócios, o Estudo objetivava estimular o desenvolvimento da infraestrutura econômica (Transporte, Energia e Telecomunicações), Desenvolvimento Social (Educação, Saúde, Habitação, e Saneamento), Meio Ambiente e Informação e Conhecimento, além de contribuir para "a melhoria da competitividade sistêmica da economia".

Baseado também no conceito de Polo de Desenvolvimento, essa análise do território brasileiro identificou os "Centros Dinâmicos do país", que "constituem os loci geradores das demandas a serem atendidas pelos investimentos" (CONSÓRCIO BRASILIANA, 2000, p. 212), e buscou diagnosticar os investimentos em empreendimentos estruturantes, ou seja, "empreendimentos com suficientes efeitos sinérgicos sobre a realidade do espaço em que se inserem, no sentido de provocar impactos positivos sobre as possibilidades de outros novos empreendimentos" (CONSÓRCIO BRASILIANA, 2000, , p. 222). $\mathrm{Na}$ verdade, a localização de tais Centros coincidiu com as áreas que já dispunham de maiores densidades técnicas e informacionais, portanto mais atrativas aos investimentos privados (ARAÚJO, 2000). Esses Centros Dinâmicos são os espaços competitivos cuja identificação foi requerida pelo Estado Nacional para alcançar uma estratégia de inserção na globalização. Em outros termos, a abordagem territorial nas análises foi tratada como um recurso para identificar os diferentes graus de competitividade de lugares e regiões do território brasileiro, por meio do alargamento da noção de região de planejamento.
Cumprindo um papel de legitimador de anseios governamentais, o Consórcio Brasiliana adotou uma fundamentação teórica que retrocedeu no tempo e desconsiderou as especificidades da formação socioespacial brasileira, conduzindo ao mais alto patamar alguns conceitos, práticas e metodologias próprias da economia espacial e sobretudo da ciência regional (BENKO, 1999) - que alcançou grande prestigio nas décadas de 1960 e 1970. Ora, torna-se bastante questionável o resgate de conceitos e metodologias atreladas a uma visão de mundo de mais de 50 anos, na medida em que o mundo mudou e se conformaram novos usos do território brasileiro.

Por conseguinte, deu-se continuidade à visão presente na proposta de Eixos, adotada primeiramente no Programa "Brasil em Ação" (1996-1999). Como assevera A.C. F. Galvão ${ }^{4}$ nesse Programa os investimentos em infraestrutura propostos iam ao encontro da narrativa da modernização conduzida pela ótica neoliberal, uma vez que todo o debate convergiu para a questão do chamado "custo-Brasil".

Já no referido estudo de 1998, a identificação de espaços capazes de apresentar maior competitividade frente aos interesses do mercado internacional foi mascarada sob o discurso da região-problema. Houve neste sentido uma equivalência entre Eixo de Desenvolvimento e Região de Planejamento, demonstrando um intenso reducionismo da riqueza conceitual subjacente à categoria de região geográfica.

Percebe-se, assim, que o planejamento territorial federal se inicia no

4 Diretor do Centro de Gestão e Estudos Estratégicos (CGEE). Entrevista concedida ao autor em abril de 2007, em Brasília - DF. 
século XXI subordinado a uma visão espacial fortemente ligada às heranças teórico-metodológicas de meados do século XX. Questões relacionadas ao desenvolvimento regional permaneciam com um tratamento pretérito, fundamentado em conceitos e metodologias incapazes de apoiar um processo político que revertesse 0 "centrifuguismo" do território brasileiro. Pouco se avançou no estabelecimento de medidas contrárias à fragmentação do território nacional, e permaneciam os conflitos entre os membros da federação, manifestados pela guerra dos lugares (SANTOS, 2002).

O Estudo dos Eixos era ineficiente para efeito de políticas de desenvolvimento regional e para a ação de outras políticas de planejamento territorial, parecendo remeter somente à necessidade de se estabelecer uma plataforma de exportação e servindo "para relacionar o Brasil próspero, aquele Brasil que está fora de nossa Política de Desenvolvimento Regional, com os mercados internacionais. ${ }^{5}$ Já nos anos 2000, houve a necessidade de se rever o Estudo dos Eixos e atualizar o Portfólio de Oportunidades de Investimentos Públicos e/ou Privados, organizado pelo Consórcio Brasiliana. Tal possibilidade ocorreu quando o BNDES lançou um edital para a contratação de um estudo visando redimensionar o Portfólio para o período de 2004 a 2011, de modo a subsidiar o Plano Plurianual (PPA) 2004-2007. Para tanto, privilegiou-se mais uma vez a participação das empresas de consultoria, em detrimento de instituições como o Ministério

\footnotetext{
5 Henrique Villa da Costa Ferreira, diretor da Secretaria de Políticas de Desenvolvimento Regional, Departamento de Planejamento de Desenvolvimento Regional, Ministério da Integração Nacional. Entrevista concedida ao autor em abril de 2007, em Brasília - DF.
}

da Integração e o próprio Ministério do Planejamento.

O Consórcio vencedor, contratado em agosto de 2002, era constituído pelas empresas de consultoria Monitor Já nos anos 2000, houve a necessidade de se rever o Estudo dos Eixos e atualizar o Portfólio de Oportunidades de Investimentos Públicos e/ou Privados, organizado pelo Consórcio Brasiliana. Tal possibilidade ocorreu quando o BNDES lançou um edital para a contratação de um estudo visando redimensionar o Portfólio para o período de 2004 a 2011, de modo a subsidiar o Plano Plurianual (PPA) 2004-2007. Para tanto, privilegiou-se mais uma vez a participação das empresas de consultoria, em detrimento de instituições como o Ministério da Integração e o próprio Ministério do Planejamento.

O Consórcio vencedor, contratado em agosto de 2002, era constituído pelas empresas de consultoria Monitor Group ${ }^{6}$ e Boucinhas \& Campos. $^{7}$ A este grupo somou-se também o Consórcio constituído pelas

\footnotetext{
${ }^{6}$ A empresa transnacional de consultoria Monitor Group tem suas raízes na Harvard Business School e apresentava, originalmente, a consultoria estratégica como principal foco de atuação, mas em anos recentes a empresa tem expandido enormemente seu campo de atuação Figuram entre seus sócios personalidades mundialmente conhecidas no campo da administração, como Michael Porter (um dos fundadores da empresa) e Peter Schwartz. Atualmente a empresa conta com cerca de 1.500 profissionais trabalhando em 26 escritórios localizados em 17 países (incluindo o Brasil) e figura entre as dez mais Prestigiosas Firmas de Consultoria do mundo, segundo o Vault Guide to the Top 50 Management and Strategy Consulting Firms 2011.

${ }^{7}$ A Boucinhas \& Campos (desde 2009 denominada Boucinhas, Campos \& Conti) é uma empresa brasileira, fundada em 1947 pelos professores José da Costa Boucinhas e Eduardo Sampaio Campos e transformou-se em uma das maiores empresas em consultoria, auditoria e serviços técnicos especializados no país. É um grupo que engloba empresas atuantes em áreas ligadas a administração, as quais reúnem cerca de 300 funcionários.
} 
empresas Booz-Allen \& Hamilton e UMAH, responsáveis pela Avaliação Ambiental Estratégica dos Investimentos na Amazônia. Convém destacar que a ação recente da empresa Monitor junto ao ex-governo ditatorial na Líbia é uma manifestação de como muitas ações de empresas de consultoria em estratégia não se pautam pela ética e pelo respeito aos princípios democráticos. ${ }^{8}$ O projeto de Atualização dos Eixos Nacionais de Integração e Desenvolvimento realizado pelo Consórcio foi dividido em cinco fases. Destaca-se, para as pretensões do presente artigo, o terceiro módulo da segunda fase do projeto, denominado "Revisão dos Determinantes de Competitividade". Seu principal objetivo foi:

[...] fornecer uma compreensão da composição microeconômica regional, através da identificação e análise dos Determinantes Críticos de Competitividade dos principais Clusters regionais, visando a contribuir para a criação da Visão Estratégica de cada Eixo e nortear a definição de ações e projetos estruturantes (CONSÓRCIO MONITOR GROUP E BOUCINHAS \& CAMPOS, Atualização dos Eixos, Relatório do Marco Inicial, 2002, p. 39).

Tal proposta - segundo os consultores - parte do princípio de que é

\footnotetext{
8 Entre 2006 e 2008, acadêmicos prestigiados como Joseph Nye e Anthony Giddens foram enviados pela empresa Monitor para reuniões com - ex-ditador da Líbia Muammar Gaddafi. Até setembro de 2010, a empresa manteve um contrato de consultoria com o Fundo de Investimentos da Previdência Líbia e estima-se que a Monitor recebia em torno de US\$ 250 mil mensais. Segundo o jornal Folha de S.Paulo, na edição de 7 de março de 2011, os serviços da Monitor focaram duas frentes: a primeira foi uma análise detalhada da economia líbia com vistas a atrair investimentos e comércio para o país após anos de sanções da ONU e a segunda foi o treinamento de "líderes em potencial", que o grupo disse ter realizado dado o "clima de otimismo com o futuro do país" (ressalta-se que o treinamento incluiu o próprio Gaddafi). Representantes da Monitor afirmaram ao referido jornal ter cometido "um erro grave" de avaliação neste caso.
}

necessário, para um processo de planejamento abrangente, a utilização de uma abordagem de aspecto microeconômico que destaque as necessidades regionais com suas atividades econômicas e demandas sociais. Neste sentido, adotou-se a metodologia de Clusters, a qual mostraria "que uma atividade econômica compõe-se de vários atores interconectados, prestando serviços, desenvolvendo tecnologias, trazendo inovações e desenvolvimento à região" (idem, 35). Essa metodologia baseiase, fundamentalmente, nos estudos de Michael Porter sobre competitividade regional.

A ideia de identificação de um Cluster é representativa do modo de agir do modelo geral de planejamento territorial proposto. O principal objetivo desta estrutura é alcançar níveis superiores de produtividade, nas escalas regional, nacional, ou internacional. Para atingir os objetivos propostos são identificados alguns "Arquétipos de Clusters", que representam as principais tipologias de Clusters existentes nos Eixos Nacionais de Integração e Desenvolvimento. Um dos principais objetivos pretendidos nesta etapa do trabalho foi a caracterização do nível de competitividade do Eixo Nacional de Integração e Desenvolvimento. Uma vez baseados nos diversos estudos desse módulo, buscou-se visualizar graficamente a ocupação econômica do espaço de abrangência de cada Eixo, de modo a permitir uma caracterização da região, sua "vocação econômica", intensidade e relevância. Mais uma vez, como no estudo do Consórcio Brasiliana, buscou-se identificar os diferentes graus de competitividade de lugares e regiões no território nacional. 
Uma vez estabelecidas uma série de etapas, propôs-se a elaboração de um Portfólio de Oportunidades de Investimentos, públicos e privados, para o período de 2004 a 2011. Esse Portfólio privilegiou setores considerados estratégicos "para a promoção da integração e do desenvolvimento sustentável dos Eixos Nacionais de Integração e Desenvolvimento" (MONITOR GROUP E BOUCINHAS \& CAMPOS, Atualização dos Eixos, Relatório do Marco Inicial, 2002, p. 59), nas dimensões de infraestrutura econômica, desenvolvimento social, meio ambiente e de informação e conhecimento. $O$ passo seguinte foi a elaboração de um Portfólio priorizado das
Oportunidades de Investimentos públicos e privados para os anos de 2004 a 2007, período do PPA do primeiro governo de Luis Inácio Lula de Silva (2003-2006).

Nesse Portfólio priorizado, os consultores estabeleceram que 0 desenvolvimento sustentável seria o critério principal para um ordenamento de importância dos agrupamentos de projetos, posto que o objetivo pretendido por esse conceito agregaria todos os demais critérios. Segundo o Consórcio em questão, a estruturação de tais critérios de análise deveria seguir uma "árvore", representada parcialmente na Figura 1.

Figura 1 - Parte da Árvore de estruturação de critérios para a análise de priorização de agrupamentos no PPA 2004-2007

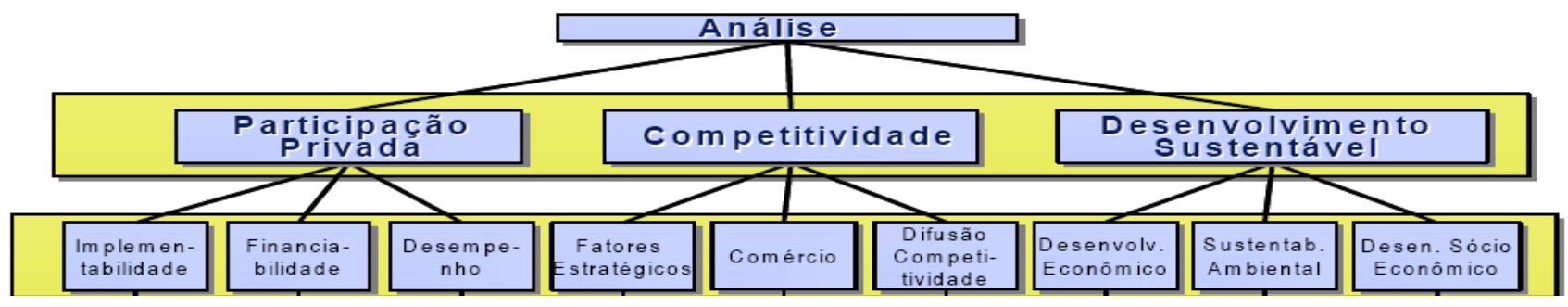

Fonte: Consórcio Monitor Group e Boucinhas \& Campos (2002).

Nota-se como os três principais "ramos" desta árvore são também os três principais eixos do planejamento territorial refuncionalizado: a participação privada, a competitividade e o desenvolvimento sustentável, sendo estes últimos fortemente presentes nos atuais estudos de planejamento governamentais. Pode-se afirmar, portanto, que há uma continuidade em alguns dos princípios basilares tratados pelos respectivos estudos de orientação ao planejamento territorial, tanto no Estudo dos Eixos (do Consórcio Brasiliana), de 1998, como nesse estudo do Consórcio Monitor Group/Boucinhas \& Campos, de 2002.
Diante do exposto, nota-se como em ambos os estudos também a noção de competitividade foi norteadora de planos de ação, autorizando, inclusive, a afirmar que a referida noção foi uma norma para o planejamento territorial no período analisado e permanece assim até os dias de hoje. Houve uma preocupação deliberada em identificar diferentes graus de competitividade de espaços utilizando a denominada abordagem territorial como um recurso, confirmando que a competitividade é também uma condição dos lugares e regiões, tal como afirmam Castillo e Frederico (2010, p. 18): 
[...] a competitividade não é um atributo circunscrito às empresas ou aos produtos no período da globalização, mas designa também uma condição dos lugares e regiões. A distribuição desigual de densidades materiais e normativas no território confere diferentes graus de competitividade às regiões para determinados tipos de produtos e, por conseguinte, a alguns agentes produtivos que nelas atuam e que delas fazem parte.

Já que a competitividade territorial pode conduzir a uma seletividade espacial e uma fragmentação territorial (VAINER, 2007), pode-se questionar a sua validade como recurso para a construção de um projeto nacional includente e equitativo. Deste modo, um planejamento territorial pautado em tais bases tem se mostrado mais conveniente para a política territorial de agentes que utilizam o território como recurso (SANTOS, 1996) e não para a totalidade da sociedade brasileira.

\section{Considerações finais}

As empresas de consultoria, sobretudo transnacionais, são conhecedoras de modelos gerenciais e detentoras de um know-how que escapa à especialização produtiva das corporações. Devido a um crescente processo de terceirização de funções, as consultorias seja de gestão, jurídica, financeira, estratégica etc. - se apresentam como uma peça crucial na estrutura produtiva que se complexiza em todo o mundo. Muitas vezes as estratégias propagadas por esses agentes e incorporadas pelas grandes empresas são dirigidas por um agir essencialmente instrumental, cujo resultado é um uso reticular dos territórios (SANTOS, 1996). Apesar disso, os preceitos adotados tornam-se princípios mimetizados pela administração pública, que entende tal conjunto de ações como condição sine qua non para a modernização das funções do Estado. Nota-se que as contribuições de grandes consultorias no planejamento territorial se dão, na maioria dos casos, por meio de procedimentos previamente delimitados, mediante atos normatizados, ações repetitivas com conteúdos científicos e, sobretudo, por meio de uma repetição de modelos apresentados como "bem-sucedidos".

Com a globalização e o imperativo da competitividade, aumenta exponencialmente a demanda do Estado brasileiro pelos serviços dessas empresas, uma vez que aparecem como o caminho mais curto para ter acesso a um conjunto de práticas cristalizadas na administração empresarial. Como resultado, esses agentes de um planejamento terceirizado, cujo dever foi avaliar novos usos para o território brasileiro, contribuíram para o aprofundamento de uma visão de modernidade excludente. Deve-se também ressaltar que, por meio de um conhecimento pormenorizado de lugares, se amplia a capacidade destas empresas de ordenarem e regularem o território nacional.

Por conseguinte, a expansão das consultorias em estratégia no campo do planejamento territorial público sem o direcionamento dado por um projeto nacional conformado pelo Estado é profundamente limitadora de um processo de construção de uma modernidade guiada por um objetivo nacional brasileiro. Portanto, pode-se afirmar que as propostas de planejamento territorial das consultorias analisadas foram ao encontro de uma concepção de espaço funcional aos interesses dos atores hegemônicos da globalização, em que o território aparece como primordial, pois a competitividade a e produtividade também se definem pelo arranjo dos lugares. 


\section{Referências bibliográficas}

ABLAS, L. O "Estudo dos Eixos" como instrumento de planejamento regional. In: GONÇALVES, M. F; BRANDÃO, C. A.; GALVÃO, A. C. F. (Orgs.). Regiões e cidades, cidades nas regiões: o desafio urbano-regional. São Paulo: Editora Unesp/Anpur, 2003, p. 171-186.

ARAÚJO, T. B. Ensaios sobre o desenvolvimento brasileiro: heranças e urgências. Rio de Janeiro: Revan/Fase, 2000.

\section{ARROYO, M. M. Território nacional e} mercado externo: uma leitura do Brasil na virada do século XX. Tese (Doutorado em Geografia) Departamento de Geografia, Faculdade de Filosofia, Letras e Ciências Humanas, Universidade de São Paulo, São Paulo, 2001.

BENKO, G. A ciência regional. Oieiras: Celta, 1999.

\section{BOUDEVILLE, J.-R. Les espaces} économiques. 3ème ed. Paris: Presses Universitaires de France, 1970.

CASTILLO, R.; FREDERICO, S. Dinâmica regional e globalização: espaços competitivos agrícolas no território brasileiro. Mercator - Revista de Geografia da UFC, ano 9, n. 18, 2010. p. 17-26.

CERNY, P. G. The limits of deregulation: transnational interpenetration and policy change. Eur. J. Political Res., n. 19,1991 , p. 173-196.

COMPANS, R. Empreendedorismo urbano: entre o discurso e a prática. São Paulo: Editora UNESP, 2005.

CONSÓRCIO BRASILIANA. Identificação de Oportunidades de Investimentos Públicos e/ou Privados. Estudo dos Eixos Nacionais de Integração e Desenvolvimento, Relatório Síntese, Tomos I e II e Apêndice Metodológico. Brasília: Ministério do Planejamento, Orçamento e Gestão, 2000.

CONSÓRCIO MONITOR GROUP E BOUCINHAS \& CAMPOS. Estudo de Atualização do Portfólio dos Eixos Nacionais de Integração e

Desenvolvimento, de 2000-2007

para 2004-2011. Relatório do Marco

Inicial. Brasília, Ministério do

Planejamento, Secretaria de

Planejamento e Investimentos

Estratégicos; Banco Nacional de

Desenvolvimento Econômico e Social, 2002.

\section{DANTAS, M. A lógica do capital}

informação: a fragmentação dos monopólios e a monopolização dos fragmentos num mundo de comunicações globais. 2. ed. Rio de Janeiro: Contraponto, 2002.

DÉTRIE, J.-P. Paysages du conseil. Revue Française de Gestion, n. 76, nov.déc. 1989, p. 6-14. Numéro Spécial.

DEZALAY, Y. O big-bang e o direito: internacionalização e reestruturação do espaço legal. FEATHERSTONE, Mike (Coord.). Cultura global: nacionalismo, globalização e modernidade. Tradução de A. Brunetta. Petrópolis: Vozes, 1994. p. 295-310.

DICKEN, P. International Production in a Volatile Regulatory Environment: the influence of National Regulatoy Policies on the Spatial Strategies of transnational Corporations.

Geoforum, v. 23, n. 3, 1992, p. 302316.

DONADONE, J. C. "Os hunos já chegaram!": dinâmica organizacional, difusão e conceitos gerenciais e a atuação das consultorias. Tese (Doutorado em Engenharia) - Escola Politécnica, Universidade de São Paulo, São Paulo, 2001.

DOSSIÊ EIXOS DE DESENVOLVIMENTO II. Relatório Gazeta Mercantil, 29 jun. 1998.

GALVÃO, A. C. F.; BRANDÃO, C. A. Fundamentos, motivações e limitações da proposta dos "Eixos Nacionais de Desenvolvimento". In: GONÇALVES, M. F.; BRANDÃO, C. A. ; GALVÃO, A. C. F. (Orgs.). Regiões e cidades, cidades nas regiões: 0 desafio urbano-regional. São Paulo: Editora Unesp/Anpur, 2003. 
LÍBIA PAGOU CONSULTORIA PARA POLIR IMAGEM. Folha de S.Paulo, São Paulo, 7 mar. 2011.

\section{LIMA JUNIOR, P. N. Uma estratégia} chamada "Planejamento Estratégico": deslocamentos espaciais de sentido na teoria do planejamento urbano. Tese (Doutorado em Planejamento Urbano e Regional) - Instituto de Pesquisa e Planejamento Urbano e Regional, Universidade Federal do Rio de Janeiro, Rio de Janeiro, 2003.

MATTOS, P. T. L. Regulação econômica e democracia: contexto e perspectivas na compreensão das agências de regulação no Brasil. In: FARIA, José E. (Org.). Regulação, direito e democracia. São Paulo: Fundação Perseu Abramo, 2002.

MENESES, M. P. Agentes do conhecimento? A consultoria e a produção do conhecimento em Moçambique. In: SANTOS, B. S. (Org.).

Conhecimento prudente para uma vida decente: um discurso sobre as ciências revisitado. São Paulo: Cortez, 2004. p. 721-755.

PERROUX, F. A economia do século $\mathbf{X X}$. Lisboa: Livraria Moraes Editora, 1967.

SANTOS, M. O país distorcido: o Brasil, a globalização e a cidadania. São Paulo: Publifolha, 2002.

. O espaço do cidadão. 4. ed. São Paulo: Nobel, 1998.
- A natureza do espaço: espaço e tempo, razão e emoção. São Paulo: Hucitec, 1996.

\section{SILVA, A. M. B. A contemporaneidade de}

São Paulo: produção de informações e novo uso do território brasileiro. Tese (Doutorado em Geografia) Departamento de Geografia, Faculdade de Filosofia, Letras e Ciências Humanas, Universidade de São Paulo, São Paulo, 2001.

SILVA, A. B.; MANZONI NETO, A. O planejamento territorial no Brasil nos anos 1990: as ações das empresas globais de consultoria (o caso da empresa Booz-Allen \& Hamilton). GEOgraphia, v. 10, n. 20, 2008, p. 53-75.

SILVEIRA, M. L. Um país, uma região: fim de século e modernidades na Argentina. São Paulo: Fapesp/Laboplan-USP, 1999.

STERN, P.; TUTOY, P. Le métier de consultant: principes, méthodes, outils. 3ème. tir. Paris: Les Éditions d'Organisation, 1995.

VAINER, C. B. Pátria, empresa e mercadoria. In: ARANTES, O. et al. A cidade do pensamento único. Petrópolis: Vozes, 2000.

VAINER, C. B. Fragmentação e projeto nacional: desafios para o planejamento territorial. XII ENCONTRO DA ASSOCIAÇÃO NACIONAL DE PÓS GRADUAÇÃO E PESQUISA EM PLANEJAMENTO URBANO E REGIONAL, maio 2007. 